\title{
Um Recorte da Produção Científica dos Egressos de um Progra- ma de Pós-Graduação Stricto Sensu em Contabilidade
}

\author{
A Cut of the Scientific Production of Former Students of a Program of Graduate Degree in \\ Accounting
}

\section{Orleans Silva Martins}

Doutorando em Ciências Contábeis pelo Programa Multiinstitucional da UNB/UFPB/UFRN

Professor da Universidade Estadual da Paraíba

Endereço: Rua Farmacêutico Antônio L. Batista, 172 - Apto 107, Bairro Jardim São Paulo

CEP: 58051-110 - João Pessoa/Paraíba - Brasil

E-mail: orleansmartins@yahoo.com.br

Telefone: (83) 8892-4970

\section{Paulo Aguiar do Monte}

Doutor em Economia pela Universidade Federal de Pernambuco (UFPE)

Professor Adjunto do Departamento de Economia da Universidade Federal da Paraíba (UFPB)

Endereço: Universidade Federal da Paraíba, Centro de Ciências Sociais Aplicadas - CCSA

Departamento de Economia . Cidade Universitária

CEP: 58059-900 - João Pessoa/Paraíba- Brasil

E-mail: pauloaguiardomonte@gmail.com

Fone: (81) 8852-6588

Artigo recebido em setembro de 2009. Passou por uma avaliação double blind review em dezembro de 2009. Aceito em janeiro de 2010 pela Editora Científica Sandra Rolim Ensslin. Artigo apresentado no II Encontro de Ensino e Pesquisa em Administração e Contabilidade (EnEPQ), 2009, Curitiba, 2009. 


\title{
Resumo
}

Este estudo teve como objetivo investigar a influência do título de mestre em Ciências Contábeis na produção científica dos mestres egressos do Programa Multiinstitucional e Inter-Regional de Pós-Graduação em Ciências Contábeis da UnB/UFPB/UFPE/UFRN. Foi realizada uma pesquisa exploratória e descritiva por meio da aplicação de um questionário aos egressos do programa e da coleta dos dados referentes à sua produção científica a partir de seus currículos Lattes. Em seus resultados, pode-se observar que apenas $30,85 \%$ dos componentes da amostra participam de algum grupo de pesquisa; que $66 \%$ dos projetos de pesquisa realizados por eles foram iniciados após o ingresso no mestrado; e que as médias de publicação de artigos em periódicos e em eventos após o ingresso no curso de mestrado são significativamente superiores às médias anteriores a este ingresso, o que comprova a influência positiva desta titulação em suas produções científicas, o que pode ser ratificado com o teste de diferença entre duas médias.

Palavras-chave: Produção Científica, Ciências Contábeis, Mestrado.

\begin{abstract}
This study aimed to investigate the influence of a master's degree in Accounting in the scientific production of masters graduates of the Program Multi-Institutional and Inter-Regional Graduate Gegree in Accounting from UNB/UFPB/UFPE/UFRN. We conducted an exploratory and descriptive research by applying a questionnaire to graduates of the program and data collection relating to his scientific production from their Lattes. In their results, we can see that only $30.85 \%$ of the components of the sample participate in some research group, $66 \%$ of research projects undertaken by them were initiated after entry into the Masters, and that the means of publishing journal articles and events after enrolling in graduate school are significantly higher than those prior to this admission, which proves the positive influence of titration in their scientific production, which can be ratified with the test of difference between two means.
\end{abstract}

Key words: Scientific Production, Accounting, Master.

\section{Introdução}

O surgimento da pós-graduação em nosso país se deu no início da década de 60, quando seus cursos eram ministrados nas universidades de forma livre, sem possuírem legislação própria. A primeira regulamentação desse tipo de curso surgiu através do Parecer no. 977/65, do extinto Conselho Federal de Educação, que foi considerado um marco na história da pós-graduação no Brasil (CUNHA, 1974; MACHADO, 2003). Desde então, estes cursos passaram a ser regulados por legislação específica do Ministério da Educação (MEC).

Até o final dos anos 90, o Brasil possuía apenas três programas de pósgraduação em Ciências Contábeis, sendo um em nível de mestrado e doutorado (USP) e outros dois apenas em nível de mestrado (PUC/SP e UERJ), todos concentrados na região Sudeste. Com isso, até o final da década passada, o Brasil possuía apenas cerca de 90 doutores e 450 mestres em Contabilidade, para um total de aproximadamente 490 cursos de graduação em Ciências Contábeis. Sendo assim, a constatação da necessidade de aperfeiçoamento do corpo docente nos 
cursos de Ciências Contábeis do Brasil, deu início a uma "corrida" pelo aumento da oferta de cursos de pós-graduação nesta área.

Nesse sentido, seguindo orientação da Coordenação de Aperfeiçoamento de Pessoal de Nível Superior (CAPES), os reitores e professores das Universidades Federais de Brasília (UnB), da Paraíba (UFPB), de Pernambuco (UFPE) e do Rio Grande do Norte (UFRN), em uma iniciativa pioneira na área contábil, celebraram um convênio de cooperação e integração técnico-científico-pedagógico, do qual resultou o Programa Multiinstitucional e Inter-Regional de Pós-Graduação em Ciências Contábeis. Este programa tem o propósito de executar programas e projetos de ensino e pesquisa em Contabilidade, buscando melhorar a qualidade desses cursos naquelas regiões. Desde então, o referido programa tem integrado as regiões Nordeste e Centro-Oeste através do ensino e da pesquisa em Contabilidade, contribuindo de forma intensiva ao desenvolvimento do ensino, pesquisa e debate de importantes temas relativos à área de estudo.

Sob esta perspectiva, o presente estudo origina uma investigação epistemológica sobre a influência do título de mestre em Ciências Contábeis na produção científica dos mestres egressos do Programa Multiinstitucional e Inter-Regional de Pós-Graduação em Ciências Contábeis da UnB/UFPB/UFPE/UFRN. Nesse sentido, a questão de pesquisa que se coloca para este estudo é: qual a influência do título de mestre em Ciências Contábeis à produção científica dos mestres egressos do Programa de Pós-Graduação em Ciências Contábeis da UnB/UFPB/ UFPE/UFRN?

\section{Fundamentação Teórica}

\subsection{A Pós-Graduação em Ciências Contábeis no Brasil}

A pós-graduação em Ciências Contábeis no Brasil surgiu no final da década de 50, mais precisamente em 12 de maio de 1958, com a promulgação do Decreto no 32.307, assinado pelo então governador do Estado de São Paulo, Jânio Quadros. Tal decreto dispõe sobre o doutoramento na Faculdade de Ciências Econômicas e Administrativas da USP, conferindo os títulos de doutor em Ciências Econômicas, doutor em Ciências Atuárias e doutor em Ciências Contábeis aos que fossem aprovados na defesa de uma tese de doutoramento perante uma banca de cinco professores e em duas disciplinas subsidiárias (CUNHA, 2007).

Com o surgimento do Parecer no 977/65 e após o início da reestruturação da pós-graduação brasileira impulsionada pela reforma universitária de 1968, em meio a um clima de reconhecimento do curso de Contabilidade da FEA/ USP como o mais bem sucedido dentre os oferecidos pela escola e como o que 
apresentava maior retorno do investimento em educação, conforme pesquisa realizada àquela época pela Fundação Instituto de Pesquisas Econômicas (FIPE) (CUNHA, 2007), em 30 de setembro de 1970, foi autorizado o primeiro curso de mestrado em Ciências Contábeis, já com o novo formato preconizado pelo parecer. Assim, a FEA/USP marcou a pós-graduação em Ciências Contábeis no Brasil como sendo a instituição pioneira a criar os cursos de doutorado e mestrado nesta área em nosso país.

Este cenário perdurou até o final da década de 70, quando no ano de 1978 a PUC/SP criou o segundo curso de mestrado em Ciências Contábeis e Atuárias do Brasil. Entretanto, o segundo curso de doutorado só veio surgir quase meio século depois do criado pela USP, em 2008, pelo Programa Multiinstitucional e InterRegional de Pós-Graduação em Ciências Contábeis, formado pela UnB, UFPB e UFRN, homologado e reconhecido pela CAPES em 28 de janeiro de 2008.

Atualmente, existem dezoito cursos de mestrado e três cursos de doutorado em Ciências Contábeis no país, após as recentes aprovações dos segundo e terceiro cursos de doutorado, pelo Programa Multiinstitucional, e, mais recentemente, pelo Programa de Pós-Graduação da Universidade Regional de Blumenal (FURB) (doutorado em Ciências Contábeis e Administração, reconhecido em 17 de abril de 2008). Segundo Niyama (2008), destes três programas de doutorado, apenas o da USP titulou doutores (165 até o dia 31 de dezembro de 2007).

Não obstante esta expansão, a criação de cursos de pós-graduação stricto sensu em Ciências Contábeis enfrentou, e até hoje enfrenta, uma grande barreira, que é a falta de professores com a titulação adequada para lecionar nestes cursos. Iudícibus e Marion (1993) observam que a falta de professores em número suficiente e com tempo integral, se na graduação é prejudicial, na pós-graduação pode ser fatal, devido às dificuldades de orientação das teses de mestrado e doutorado.

Assim, objetivando representar os Programas de Pós-Graduação em Ciências Contábeis perante os agentes com os quais se relacionam e fortalecer o ensino e a pesquisa em Contabilidade no país, em 30 de janeiro de 2006 foi fundada a Associação Nacional de Programas de Pós-Graduação em Ciências Contábeis (ANPCONT), uma associação sem fins lucrativos, sediada na cidade de São Paulo. A ANPCONT tem por objetivo atuar na área de educação, congregando e representando as IES brasileiras que mantêm cursos de mestrado e/ ou doutorado. Com isso, ela busca fortalecer a pós-graduação em Contabilidade através de atividades como: o intercâmbio entre as IES associadas; a realização de pesquisas; a divulgação de trabalhos e estudos técnicos, inclusive, publicando livros e revistas; o desenvolvimento e a organização de um banco de dados sobre a pós-graduação em Ciências Contábeis; a promoção de cursos, treinamentos e congressos; o oferecimento de bolsas e prêmios como estímulo aos seus objetivos; entre outras atividades. 


\subsubsection{O Mestrado em Ciências Contábeis}

Após a criação do primeiro mestrado em Contabilidade no ano de 1970, até o ano de 1999 o Brasil possuía apenas três programas de pós-graduação em Ciências Contábeis recomendados pela CAPES. Atualmente, existem dezoito programas recomendados por esta instituição. Destes, quatro são na modalidade de mestrado profissional e quatorze na modalidade de mestrado acadêmico. Dos dezoito, apenas seis são particulares, os demais são públicos (NIYAMA, 2008). Ressalta-se, entretanto, o pioneirismo do Programa Multiinstitucional (ainda com a participação da UFPE) com seu programa de mestrado acadêmico iniciado no ano de 2000, o primeiro criado fora do eixo Sul/Sudeste do Brasil.

Atualmente, além do Programa Multiinstitucional, a região Nordeste possui outros três programas com mestrado em Ciências Contábeis (UFPE, UFBA e UFC) e a região Centro-Oeste permanece unicamente com o Multiinstitucional. A região Norte possui apenas um programa de mestrado profissional (UFAM) e os demais 72,22\% dos cursos de mestrado em Ciências Contábeis (13) são oferecidos nas regiões Sul e Sudeste do país, como se observa no Quadro 1.

Quadro 1: Brasil. Cursos de pós-graduação com área de concentração em Contabilidade, Controladoria, Controladoria e Contabilidade e Ciências Contábeis.

\begin{tabular}{|c|c|c|c|c|c|}
\hline IES & Região & Estado & Tipo & $\begin{array}{c}\text { Ano do } \\
\text { Reconhecimento }\end{array}$ & Conceito \\
\hline FUCAPE & Sul & ES & Mestrado Profissional & 2003 & 4 \\
\hline UFMG & Sudeste & MG & Mestrado & 2007 & 3 \\
\hline UFPE & Nordeste & $\mathrm{PE}$ & Mestrado & 2006 & 3 \\
\hline UFRJ & Sudeste & RJ & Mestrado & 1999 & 4 \\
\hline UERJ & Sudeste & RJ & Mestrado & 2006 & 3 \\
\hline UNISINOS & Sul & $\mathrm{RS}$ & Mestrado & 2001 & 4 \\
\hline FURB & Sul & $\mathrm{SC}$ & Mestrado/Doutorado & 2006 & 3 \\
\hline UPM & Sudeste & SP & Mestrado Profissional & 2008 & 4 \\
\hline UNIFECAP & Sudeste & SP & Mestrado & 2001 & 3 \\
\hline $\mathrm{PUC/SP}$ & Sudeste & SP & Mestrado & 2006 & 3 \\
\hline UFBA & Nordeste & $\overline{\mathrm{BA}}$ & Mestrado & 2007 & 3 \\
\hline UFPR & Sul & $\mathrm{PR}$ & Mestrado & 2006 & 3 \\
\hline UFSC & Sul & $\mathrm{SC}$ & Mestrado & 2004 & 3 \\
\hline UnB/UFPB/UFRN & \begin{tabular}{|c|} 
Nordeste/ \\
Centro-Oeste
\end{tabular} & Brasília/PB/RN & Mestrado/Doutorado & 2000 & 4 \\
\hline UFAM & Norte & AM & Mestrado Profissional & 2007 & 3 \\
\hline UFC & Nordeste & $\mathrm{CE}$ & Mestrado Profissional & 2003 & 3 \\
\hline USP & Sudeste & SP & Mestrado/Doutorado & 2001 & 5 \\
\hline USP/RP & Sudeste & SP & Mestrado & 2001 & 3 \\
\hline
\end{tabular}

Fonte: Adaptado de Cunha (2007, p. 17).

Segundo Silva (2008), o processo de desenvolvimento regional depende do estabelecimento de políticas específicas para cada região. A criação e consolidação 
de cursos de pós-graduação strictu sensu são fatores fundamentais para a formação de cidadãos críticos, com habilidades e competências para intervir afirmativamente nos processos sociais e políticos locais e regionais. O sistema de pós-graduação no Brasil é nacional, mas deve contemplar diferenças e especificidades regionais. Ainda, segundo Peleias et. al (2007), a criação desse tipo de programa no Brasil tem semeado condições necessárias para o aumento da produção científica em Contabilidade, e esse crescimento tem levado a uma maior presença de trabalhos de pesquisa em Contabilidade em importantes eventos científicos brasileiros e internacionais. Dessa forma, considerando-se a importância da regionalização da política de pós-graduação e a necessidade de criação de programas temáticos e multidisciplinares que respondam às especificações e vocações das regiões, observa-se que o Brasil ainda necessita de uma política mais descentralizadora quanto a este tipo de qualificação profissional.

Investigando o total de mestres titulados por estes dezoito programas, e, por outros dois atualmente não recomendados pela CAPES (Fundação Visconde de Cairu - FVC - e Unopar), até o dia 31 de dezembro de 2007 o Brasil possuía 1699 mestres em Ciências Contábeis. A taxa média de crescimento da quantidade de mestres nos últimos três anos girou em torno de 18,30\% ao ano (2005: 26,50\%; 2006: $16,11 \%$; 2007: 12,29\%). O programa que mais titulou mestres continua sendo o da USP, com 446 titulados, seguido pelos programas da PUC/SP (208), da FECAP (205) e da UnB/UFPB/UFRN (137), conforme Quadro 2.

Quadro 2: Brasil. Quantidade de mestres titulados por programa de pós-graduação. 2004-2007

\begin{tabular}{|c|c|c|c|c|c|}
\hline \multirow{2}{*}{ Instituição } & \multirow{2}{*}{ Estado } & \multicolumn{4}{|c|}{ Total Acumulado por Programa } \\
\cline { 3 - 6 } & & $\mathbf{2 0 0 4}$ & $\mathbf{2 0 0 5}$ & $\mathbf{2 0 0 6}$ & $\mathbf{2 0 0 7}$ \\
\hline USP & SP & 398 & 421 & 441 & 446 \\
\hline PUC/SP & SP & 179 & 208 & 208 & $208^{*}$ \\
\hline FECAP & SP & 114 & 153 & 180 & 205 \\
\hline UnB/UFPB/UFRN & Brasília/PB/RN & 54 & 79 & 105 & 137 \\
\hline FUCAPE & ES & 23 & 36 & 73 & 111 \\
\hline UNISINOS & RS & 56 & 71 & 87 & 103 \\
\hline FURB & SC & - & 52 & 75 & 88 \\
\hline UFRJ & RJ & 50 & 58 & 75 & 83 \\
\hline UERJ & RJ & 23 & 35 & 35 & $53 * *$ \\
\hline UFC & CE & - & 25 & 25 & 45 \\
\hline UFSC & SC & - & - & 4 & 11 \\
\hline UFPR & PR & - & - & - & 4 \\
\hline USP/RP & SP & - & - & 4 & $4 *$ \\
\hline UFMG & MG & - & - & - & - \\
\hline UFBA & BA & - & - & - & - \\
\hline UFPE & PE & - & - & - & - \\
\hline UFAM & AM & - & - & - & - \\
\hline UPM & SP & - & - & - & - \\
\hline FVC & BA & 90 & 122 & 158 & 158 \\
\hline UNOPAR & PA & 43 & 43 & 43 & 43 \\
\hline TOOTAL GERAL & $\mathbf{1 . 0 3 0}$ & $\mathbf{1 . 3 0 3}$ & $\mathbf{1 . 5 1 3}$ & $\mathbf{1 . 6 9 9}$ \\
\hline
\end{tabular}

* Não incluído o ano de 2007. ** Não incluído o ISEC. 
Considerando-se apenas os programas atualmente recomendados pela CAPES, tem-se 1.498 mestres titulados, enquanto os demais 201 foram titulados pelas descredenciadas FVC e Unopar. Relacionando-se a quantidade de mestres titulados até aquela data e a quantidade de cursos de graduação em Ciências Contábeis naquele mesmo período (1070), tem-se cerca de 1,59 mestres para cada curso de graduação. Relacionando-se o número de mestres com o de doutores em Ciências Contábeis, para cada doutor titulado no país até 31 de dezembro de 2007, tem-se 10,3 mestres.

\subsection{O Programa Multiinstitucional e Inter-Regional de Pós-Graduação em Ciências Contábeis da UnB/UFPB/UFPE/UFRN}

A discussão da criação de programas de cooperação interinstitucional vem sendo feita no Brasil há vários anos, tendo sido mencionados como possibilidade desde o III Plano Nacional de Pós-Graduação (PNPG), através dos programas por consórcio. Isso foi refletido no V Encontro Nacional de Pró-Reitores de Pesquisa e Pós-Graduação, realizado em 1989, onde o tema "Cooperação Interuniversitária" foi amplamente discutido (CAPES, 1996). Desde então, o número de projetos de cooperação interinstitucional cresceu muito, forçados, principalmente, pela necessidade de implantação de propostas criativas que suplantassem os obstáculos individuais de criação de programas de pós-graduação pelas IES brasileiras.

Nesse contexto, após constatação da inevitabilidade de criação de novos cursos de pós-graduação stricto sensu em Ciências Contábeis no Brasil devido às exigências da $\mathrm{LDB}^{1}$ e, sabendo-se que nenhuma das Instituições Federais de Ensino Superior (IFES) possuíam, isoladamente, condições para criar um curso desse porte, buscou-se estimular os representantes de algumas IFES a procurarem soluções para este impasse. Nesse sentido, delineou-se a possibilidade de que quatro das instituições mais interessadas na proposta pudessem unir esforços com o objetivo de implementar um programa multiinstitucional na área das Ciências Contábeis, o que seria uma iniciativa pioneira nesta área, segundo representantes da CAPES.

Sendo assim, em 12 de novembro de 1999 os reitores das Universidades Federais de Brasília (UnB), da Paraíba (UFPB), de Pernambuco (UFPE) e do Rio Grande do Norte (UFRN) juntaram esforços e, com a consolidação de um corpo docente com titulação adequada, celebraram um convênio de cooperação e intercâmbio técnico-científico-pedagógico, do qual resultou um programa de pós-graduação stricto sensu em Ciências Contábeis, com o objetivo de executar programas e projetos de ensino e pesquisa nas áreas de interesse conjunto.

Desta forma, os professores integrantes das quatro IFES que formaram o corpo docente do programa formalizaram o projeto pedagógico do Curso de 
Mestrado em Ciências Contábeis do Programa Multiinstitucional junto à CAPES, o qual obteve sua aprovação pela instituição, através do Ofício CAA/CTC/59 em 20 de junho de 2000. Nessa aprovação, o Programa recebeu o conceito 3, que considerava a proposta inovadora e relevante à medida que fazia bom uso dos recursos disponíveis nas instituições participantes. Não obstante essa conceituação, atualmente o programa possui conceito 4, ficando atrás apenas do Programa da FEA/USP (conceito 5) (UNB, 2008a).

Deste modo, o quinto Programa de Mestrado em Ciências Contábeis do Brasil surgiu com os seguintes objetivos:

- Oferecer Curso de Mestrado em Ciências Contábeis nas instituições de ensino participantes do Programa (UnB, UFPB, UFPE e UFRN), em apoio à política de formação de pessoal para as instituições que desenvolvem programas de ensino, pesquisa e extensão em áreas do conhecimento relacionadas com as Ciências Contábeis;

- Desenvolver atividades de ensino e pesquisa em Ciências Contábeis e áreas afins nessas quatro instituições federais de ensino, de modo a contribuir para o avanço econômico e social do país;

- Contribuir para o desenvolvimento do conhecimento em Ciências Contábeis no Brasil e, particularmente, nas regiões Nordeste e Centro-Oeste do país, que são as áreas de abrangência das instituições participantes.

Junto à CAPES, ele aparece sob a rubrica da UnB, no entanto, representa atualmente o Programa Multiinstitucional e Inter-Regional de Pós-Graduação em Ciências Contábeis da UnB/UFPB/UFRN, o Programa apresenta uma única área de concentração denominada "Mensuração Contábil", a qual se desdobra em três linhas de pesquisa: "Contabilidade para Tomada de Decisão", "Contabilidade e Mercado Financeiro" e "Impactos da Contabilidade para a Sociedade". Ainda, segundo a CAPES, a estrutura curricular está adequadamente definida, considerando, inclusive, a logística de atendimento de disciplinas em três diferentes campi.

O mestrado funciona em dois núcleos e disponibiliza 12 vagas por núcleo anualmente. $\mathrm{O}$ núcleo Brasília teve sua primeira turma iniciada em agosto de 2000, enquanto o Nordeste a iniciou em março de 2001. O de Brasília funciona nas dependências da Universidade de Brasília, enquanto que o núcleo Nordeste funciona nas dependências das Universidades Federais da Paraíba, de Pernambuco e do Rio Grande do Norte. Assim, o Programa conta com uma Coordenação Geral e Três Regionais (atualmente sem a presença da UFPE). A Coordenação Geral fica a cargo da UnB, a qual é a responsável pela emissão dos diplomas, e as Coordenações Regionais ficavam a cargo das demais instituições (UFPB, UFRN e UFPE'²).

Frente a este cenário, a UnB ocupa papel importante na gestão do Pro- 
grama. Como citado por Darcy Ribeiro na proposta de criação da Universidade (1962 apud MOREL, 1979), através de seu Plano Orientador, a UnB seria criada com a intenção de superar e corrigir os erros das escolas superiores tradicionais e das universidades conglomeradas existentes até então. Assim, a instituição desempenharia papel dos mais importantes na implantação da pesquisa científica, no estabelecimento do regime de dedicação exclusiva para os professores e na criação de cursos de pós-graduação para formação e ampliação de quadros de pessoal docente e de especialistas e profissionais altamente qualificados. Com a criação do Programa, a UnB fortalece o cumprimento de seu objetivo e coopera com a qualificação do ensino e da pesquisa na área das Ciências Contábeis.

Prova disto é que, segundo a Secretaria de Planejamento (SPL) da UnB, até o final do segundo semestre de 2007 o mestrado em Ciências Contábeis registrava o ingresso de 204 alunos, sendo 135 homens e 69 mulheres, distribuídos em 16 semestres, como pode ser observado no Quadro 3.

Quadro 3: UnB. Mestrado em Ciências Contábeis: Ingressantes por Semestre. 2000 - 2007

\begin{tabular}{|c|c|c|c|}
\hline \multirow{2}{*}{ Semestre } & \multicolumn{2}{|c|}{ Gênero } & \multirow{2}{*}{ Total } \\
\cline { 2 - 3 } & Masculino & Feminino & \\
\hline 2000.1 & 1 & 0 & 1 \\
\hline 2000.2 & 13 & 1 & 14 \\
\hline 2001.1 & 10 & 5 & 15 \\
\hline 2001.2 & 5 & 1 & 6 \\
\hline 2002.1 & 9 & 3 & 12 \\
\hline 2002.2 & 9 & 3 & 12 \\
\hline 2003.1 & 9 & 6 & 15 \\
\hline 2003.2 & 8 & 1 & 9 \\
\hline 2004.1 & 7 & 11 & 18 \\
\hline 2004.2 & 6 & 6 & 12 \\
\hline 2005.1 & 15 & 9 & 24 \\
\hline 2005.2 & 9 & 3 & 12 \\
\hline 2006.1 & 13 & 5 & 18 \\
\hline 2006.2 & 7 & 5 & 12 \\
\hline 2007.1 & 8 & 5 & 13 \\
\hline 2007.2 & 6 & 5 & 11 \\
\hline Total & $\mathbf{1 3 5}$ & $\mathbf{6 9}$ & $\mathbf{2 0 4}$ \\
\hline
\end{tabular}

Fonte: UnB (2008b).

Ainda, de acordo com a mesma fonte, do início do mestrado até o final do segundo semestre de 2007, a SPL da UnB registrava apenas 12 desligamentos de alunos do curso, sendo: 4 através de abandono pelo aluno (todos homens), 4 por falta de rendimento acadêmico (3 homens e 1 mulher) e 4 por jubilamento (3 homens e 1 mulher). 


\subsubsection{A Saída da UFPE do Programa}

Classificado como inovador e coerente pela CAPES por ter feito bom uso dos recursos disponíveis nas instituições proponentes, o Programa perdurou por cerca de seis anos com a formação inicial, quando no ano de 2006, motivada pela existência de divergências entre os gestores do Programa, a UFPE decidiu desvincular-se do mesmo, submetendo à CAPES um projeto independente de mestrado em Contabilidade. Em 2007, a CAPES aprovou e recomendou a criação do programa independente. Desta forma, o último processo seletivo envolvendo as quatro instituições foi o do segundo semestre de 2006.

Diante deste cenário, as IFES remanescentes (UnB, UFPB e UFRN) decidiram criar um novo consórcio baseado na experiência anterior, dando origem ao Programa Multiinstitucional e Inter-Regional de Pós-Graduação em Ciências Contábeis da UnB/UFPB/UFRN. Este Programa manteve os conceitos e características do anterior, diferenciando-se somente pelo fato de ter apenas três IFES em sua estrutura e por possuir o curso de doutorado em Ciências Contábeis.

\subsubsection{A Aprovação do Doutorado}

Desde a elaboração do primeiro projeto do Programa Multiinstitucional, os professores vinculados às quatro instituições definiram que o mesmo seria iniciado com um curso de mestrado, sendo que após a consolidação desta etapa seria dado início ao curso de doutorado.

Nesse sentido, em 2005 foi submetido à CAPES o primeiro projeto de criação do curso de doutorado em Ciências Contábeis do Programa Multiinstitucional envolvendo as quatro instituições (UnB, UFPB, UFPE e UFRN). Tal projeto foi acompanhado e avaliado pela CAPES, o qual recebeu a aprovação pela referida instituição em fevereiro de 2007, no entanto, não chegou a funcionar devido à existência de divergências internas entre as instituições e à conseqüente saída da UFPE do consórcio, o que fez com que o Programa fosse reformulado apenas com as IFES permanecentes. Assim, após esta fase, o projeto foi alterado e submetido novamente em meados de 2007 , desta vez composto apenas pelas três IFES, o qual recebeu aprovação e recomendação pela CAPES no dia 28 de Janeiro de 2008, com conceito 4.

O curso teve sua primeira turma montada já no início do ano de 2008, com 8 alunos. Recentemente (novembro de 2008) realizou seu segundo processo seletivo para a formação da segunda turma em 2009, disponibilizando 8 (oito) vagas, sendo 4 destinadas aos alunos componentes do núcleo Brasília e 4 para os componentes do núcleo Nordeste ( 2 para a UFPB e 2 para a UFRN). 


\section{Aspectos Metodológicos}

\subsection{Caracterização do Estudo}

O presente trabalho apresenta-se como pesquisa exploratória, tendo em vista que objetiva proporcionar maior familiaridade com o tema investigado. Nesse sentido, o tema será explorado através das respostas dos egressos ao questionário e da análise de seus currículos, confrontando-se essas informações a fim de verificar a existência de algum viés. Também pode ser classificado como quantitativo, tendo em vista sua natureza, e descritivo, uma vez que tem como objetivo descrever as características de determinada população, estabelecendo relações entre as variáveis (SILVA, 2003). Dessa forma, os resultados obtidos através da pesquisa exploratória contribuem no sentido de identificar relações existentes entre as variáveis estudadas desta população (BEUREN, 2006). Já o estudo descritivo, descreve suas principais características. Assim, no que diz respeito aos fins, esta pesquisa caracteriza-se como um estudo explotarório-descritivo.

\subsection{Método e Técnicas}

O método que apóia a pesquisa é o indutivo que, segundo Richardson (2008), parte das premissas dos fatos observados para se chegar a uma conclusão que contenha informações sobre fatos ou situações não observadas, perfazendo o caminho do particular para o geral.

As técnicas de investigação que foram utilizadas na elaboração do estudo foram a pesquisa bibliográfica, constituindo parte da pesquisa descritiva, através da qual foi possível investigar o estado da arte da pós-graduação em Ciências Contábeis no Brasil e a história do Programa Multiinstitucional, e a pesquisa documental, através da qual foi possível realizar um levantamento de documentos do Programa e dos currículos Lattes publicados na Plataforma Lattes do Conselho Nacional de Desenvolvimento Científico e Tecnológico (CNPq).

\subsection{Procedimentos estatísticos}

O principal objetivo de uma análise estatística é extrair informações dos dados coletados, estabelecendo relações entre objetos e variáveis. Nesse sentido, buscando ratificar os resultados encontrados nas análises dos dados, foram realizados testes estatísticos com o auxílio do software SPSS, objetivando analisar as relações existentes entre as variáveis investigadas.

\subsubsection{Teste de Diferença Entre Duas Médias}


Durante a realização de uma análise estatística, em muitas situações os elementos são coletados como pares de valores de uma mesma amostra, tal quando se determina o nível de produtividade de cada trabalhador antes e depois de um programa de treinamento (KAZMIER, 1982). Nesse sentido, o teste de diferença entre duas médias objetiva investigar se as diferenças entre as médias dos pares que compõem uma amostra emparelhada são estatisticamente significativas ou não. Para tanto, foram calculadas as correlações de Pearson entre as duas variáveis e analisadas as diferenças entre médias a um nível de significância de 5\% $(\alpha=0,05)$, adotando-se o valor do t-tabelado de 1,96 . Dessa forma, têm-se as seguintes hipóteses:

$\mathrm{H}_{0}: \mu_{1}=\mu_{2} \quad\left(\mu_{1}-\mu_{2}=0\right) \rightarrow$ Não há diferença estatisticamente significativa.

$\mathrm{H}_{1}: \mu_{1} \neq \mu_{2} \quad\left(\mu_{1}-\mu_{2} \neq 0\right) \rightarrow$ Há diferença estatisticamente significativa.

Tendo em vista que o tipo de análise realizada neste trabalho diz respeito às médias da produção científica dos egressos do Programa em diferentes momentos, investigou-se a possibilidade de aceitação (tcal < ttab) ou rejeição (tcal > ttab) da hipótese nula (H0), objetivando verificar se as diferenças entre as médias de produção apresentadas pelos egressos antes, durante e após o mestrado são significativas ou não.

\subsection{Coleta e Análise dos Dados}

Inicialmente, o processo de coleta de dados para a realização da pesquisa foi realizado a partir dos currículos Lattes dos 137 mestres que representaram a população investigada, no dia 12 de junho de 2008. No entanto, após esta etapa constatou-se a inexistência do currículo de 6 egressos e, ainda, que vários dos currículos mantidos naquela base se encontravam desatualizados. Sendo assim, decidiu-se aplicar um questionário a esses egressos solicitando dados relativos à sua produção científica e informações referentes ao perfil e ao núcleo no qual o egresso concluiu seu curso.

Nesse sentido, foi realizado o pré-teste desse questionário junto a amostra piloto de seis especialistas. Em seguida, tal instrumento foi enviado aos mestres através de seus e-mails, durante os meses de julho e agosto de 2008, obtidos junto à coordenação do Programa e à base de dados da Plataforma Lattes. Do total de questionários enviados, foram obtidas 92 respostas, além de 4 questionários aplicados pessoalmente, totalizando 96 respondentes, representando 70,07\% da população investigada. Dessa forma, as informações obtidas por meio do questionário foram cruzadas com os dados coletados a partir da Plataforma Lattes.

Para a análise e interpretação dos resultados, os dados foram tabulados no 
software Excel e, posteriormente, extraídos para o pacote estatístico SPSS 16.0.1, onde foram realizados testes de diferença entre duas médias buscando ratificar os resultados observados na análise descritiva.

\subsection{População e Amostra}

A população alvo da pesquisa compreendeu 137 mestres em Ciências Contábeis egressos do Programa Multiinstitucional que defenderam suas dissertações no período compreendido entre agosto de 2002 e dezembro de 2007 . Tendo em vista o pequeno número de elementos da população, buscou-se localizar um número de egressos que garantisse estatisticamente a generalização das características observadas à população total, com um nível de confiança pré-estabelecido. Para que esta amostra representasse com fidedignidade as características do universo, buscou-se compô-la por um número suficiente de elementos, estabelecendo seu nível de confiança, seu erro máximo permitido e a percentagem esperada de respostas recebidas. Sendo assim, baseando-se em Gil (1999), foi estabelecido um nível de confiança de $95 \%(\sigma=1,96)$, a percentagem de respostas esperadas $(\mathrm{p}=$ $0,70)$, a percentagem complementar $(q=0,30)$ e o erro máximo permitido para a amostra $(\mathrm{e}=0,05)$, como se segue:

$$
\mathrm{n}=\frac{\sigma^{2} \cdot p \cdot q \cdot \mathrm{N}}{e^{2}(\mathrm{~N}-1)+\sigma^{2} \cdot p \cdot q} \mathrm{n}=\frac{1,96^{2} \cdot 0,70 \cdot 0,30 \cdot 137}{0,05^{2}(137-1)+1,96^{2} \cdot 0,70 \cdot 0,30} \quad \mathrm{n}=\mathbf{9 6 , 3 8 0 3 6 3 0 5}
$$

Desta forma, estabeleceu-se o tamanho da amostra em 96 elementos.

\section{Síntese dos Resultados}

A análise da produção científica mestres em Ciências Contábeis egressos deste programa teve como base uma amostra de 131 mestres, uma vez que seis deles não mantinham o referido currículo na Plataforma Lattes do CNPq (representando 4,38\% da população investigada). Quanto aos respondentes do questionário, do total de 96, não foram encontrados os currículos de apenas 2 (dois).

Desta forma, investigou-se a variação da produção científica destes profissionais a partir de quatro variáveis, que são elas: participação em grupo de pesquisa (GP); participação/coordenação de projeto de pesquisa (PP); publicação de artigos em periódicos (AP); e publicação de artigos em eventos (congressos, simpósios, encontros, dentre outros, recomendados pela CAPES) (AE). A composição da variável grupo de pesquisa foi realizada pela participação ou não do respondente no referido grupo. Para a variável projeto de pesquisa, foi considerada a participação 
do respondente, seja como mero integrante do projeto ou como coordenador. A variável artigos publicados em periódicos foi composta pelos trabalhos publicados em periódicos, ranqueados ou não pela CAPES. Já a composição da variável artigos publicados em eventos, foi composta apenas por trabalhos publicados em anais de eventos ranqueados pela CAPES. Nesse sentido, para a determinação dos intervalos de classificação das variáveis, foi considerado o ano de ingresso e conclusão do mestrado pelo respondente, classificando-os em antes do mestrado, durante o mestrado e após o mestrado.

\subsection{Análise da Produção Científica da População Total}

A primeira análise realizada foi relativa à produção científica da população total objeto de estudo. A partir da análise dos 131 currículos encontrados, constatou-se que $27,48 \%$ dos mestres titulados por este programa participam de algum grupo de pesquisa (enquanto $72,52 \%$ deles não possuíam nenhum vínculo com grupos de pesquisa). Quanto à participação dos mestres em projetos de pesquisa e à publicação de artigos em periódicos e eventos, observa-se que, após o ingresso no mestrado, há um significativo aumento deste tipo de produção. Quando a análise se concentra na participação de projetos de pesquisa, observa-se que, do total de projetos concluídos e em andamento apresentados pelos mestres, 34\% (17 projetos) tiveram seu início antes do ingresso no mestrado, 16\% (8 projetos) foram produzidos durante o decurso do mestrado e outros $50 \%$ foram produzidos após sua conclusão.

Já quando o foco é a quantidade de artigos produzidos pelos egressos, essa diferença é ainda mais significativa. Antes do ingresso no mestrado, a média de artigos produzidos e publicados em algum periódico, por cada mestre, era de 0,14 artigos. Após a conclusão do mestrado, ela sobe para 0,76 artigos/mestre. Do total de artigos produzidos e publicados em periódicos até a data de corte da pesquisa (195 artigos), cerca de 9,24\% (18 artigos) foram publicados no período anterior ao ingresso no mestrado, $42,05 \%$ ( 82 artigos) foram publicados no período durante o decurso do mestrado e 48,71\% (95 artigos) após a conclusão do mestrado. Ou seja, 90,74\% das publicações de artigos em periódicos ocorreram nos períodos durante ou após o mestrado, o que denota a influência do referido título na produção científica do egresso, como pode ser observado na Tabela 1. 


\begin{tabular}{|c|c|c|c|c|c|c|c|c|}
\hline \multirow{2}{*}{ Variável } & \multicolumn{2}{|c|}{ Produção } & \multirow{2}{*}{ Mín. } & \multirow{2}{*}{ Máx. } & \multirow{2}{*}{ Média } & \multirow{2}{*}{ Erro } & \multirow{2}{*}{$\begin{array}{l}\text { Desvio } \\
\text { Padrão }\end{array}$} & \multirow{2}{*}{ Variância } \\
\hline & $\mathbf{N}$ & $\%$ & & & & & & \\
\hline \multicolumn{9}{|l|}{ Participação em Projetos de Pesquisa } \\
\hline Antes do mestrado & 17 & 34,00 & 0 & 4 & 0,14 & 0,05 & 0,60 & 0,38 \\
\hline Durante o mestrado & 8 & 16,00 & 0 & 2 & 0,06 & 0,03 & 0,33 & 0,11 \\
\hline Após o mestrado & $\underline{25}$ & $\underline{50,00}$ & 0 & 5 & 0,20 & 0,06 & 0,72 & 0,52 \\
\hline Total & 50 & $\overline{100,00}$ & & & & & & \\
\hline \multicolumn{9}{|l|}{ Artigos Publicados em Periódicos } \\
\hline Antes do mestrado & 18 & 9,24 & 0 & 5 & 0,14 & 0,05 & 0,52 & 0,35 \\
\hline Durante o mestrado & 82 & 42,05 & 0 & 4 & 0,66 & 0,09 & 0,96 & 0,92 \\
\hline Após o mestrado & $\underline{95}$ & $\underline{48,71}$ & 0 & 10 & 0,76 & 0,15 & 1,70 & 2,88 \\
\hline Total & $\overline{195}$ & $\overline{100,00}$ & & & & & & \\
\hline \multicolumn{9}{|l|}{ Artigos Publicados em Anais de Eventos } \\
\hline Antes do mestrado & 95 & 9,26 & 0 & 17 & 0,76 & 0,21 & 2,30 & 5,30 \\
\hline Durante o mestrado & 568 & 55,36 & 0 & 23 & 4,54 & 0,38 & 4,28 & 18,28 \\
\hline Após o mestrado & $\underline{363}$ & $\underline{35,38}$ & 0 & 39 & 2,90 & 0,62 & 6,90 & 47,64 \\
\hline Total & $\overline{1.026}$ & $\overline{100,00}$ & & & & & & \\
\hline
\end{tabular}

Fonte: Dados da pesquisa.

Estes resultados vêm ratificar o observado por Velloso e Velho (2001) junto aos mestrandos e doutorandos do país, quando os autores observaram que, geralmente, os mestrandos da área das Ciências Sociais Aplicadas não haviam publicado artigos ou trabalhos antes de ingressarem no curso, centralizando este tipo de produção nos períodos pós-ingresso no curso (durante e após o curso). Isto pode ser notado, também, quando se observa a quantidade máxima de projetos e artigos produzidos por estes mestres, ao passo que os períodos pós-mestrado sempre apresentam valores superiores aos demais.

Focando a análise na produção e publicação de artigos em eventos ranqueados pela CAPES, percebe-se que essa influência é igualmente significativa. De um total de 1.026 artigos publicados, $9,26 \%$ (95 artigos) foram publicados no período anterior ao ingresso no mestrado, $55,36 \%$ (568 artigos) foram publicados no período de decurso do mestrado e 35,38\% (363 artigos) após a conclusão do mestrado. Estes percentuais denotam que a produção e publicação de artigos em eventos se concentram, em sua maioria, durante o período no qual o mestre está cursando o seu mestrado, apresentando um decréscimo na quantidade de trabalhos publicados após a conclusão do curso. A média de trabalhos publicados pelos mestres durante o período que estão cursando o mestrado é de 4,54 artigos/mestre. Já no período pós-mestrado, essa média cai para 2,90 artigos/mestre.

Sendo assim, buscando ratificar a significância das diferenças de médias de trabalhos publicados durante estes períodos, foi realizado um teste de diferença entre duas médias, cujos resultados podem ser observados na Tabela 2.

Tabela 2: Teste $t$ de diferença entre duas médias para amostras emparelhadas - popula- 
ção total

\begin{tabular}{|c|c|c|c|c|c|c|c|c|c|}
\hline \multirow{3}{*}{\multicolumn{2}{|c|}{ Pair }} & \multicolumn{5}{|c|}{ Paired Differences } & \multirow[b]{3}{*}{$\mathrm{T}$} & \multirow[b]{3}{*}{ DF } & \multirow{3}{*}{$\begin{array}{c}\text { Sig. } \\
\text { (2-tailed) }\end{array}$} \\
\hline & & \multirow[b]{2}{*}{ Mean } & \multirow{2}{*}{$\begin{array}{c}\text { Std. } \\
\text { Deviation }\end{array}$} & \multirow{2}{*}{$\begin{array}{l}\text { Std. } \\
\text { Error } \\
\text { Mean }\end{array}$} & \multicolumn{2}{|c|}{$\begin{array}{c}95 \% \\
\text { Confidence } \\
\text { Interval of the } \\
\text { Difference }\end{array}$} & & & \\
\hline & & & & & Lower & Upper & & & \\
\hline Pair 1 & PP Antes - PP Durante & 0,072 & 0,584 & 0,052 & $-0,031$ & 0,175 & 1,377 & 124 & 0,171 \\
\hline Pair 2 & PP Antes - PP Depois & $-0,064$ & 0,716 & 0,064 & $-0,191$ & 0,063 & $-1,000$ & 124 & 0,319 \\
\hline Pair 3 & AP Antes - AP Durante & $-0,512$ & 1,021 & 0,091 & $-0,693$ & $-0,331$ & $-5,607$ & 124 & 0,000 \\
\hline Pair 4 & AP Antes - AP Depois & $-0,616$ & 1,791 & 0,160 & $-0,933$ & $-0,299$ & $-3,846$ & 124 & 0,000 \\
\hline Pair 5 & AE Antes - AE Durante & $-3,784$ & 4,340 & 0,388 & $-4,552$ & $-3,016$ & $-9,749$ & 124 & 0,000 \\
\hline Pair 6 & AE Antes - AE Depois & $-2,144$ & 7,156 & 0,640 & $-3,411$ & $-0,877$ & $-3,350$ & 124 & 0,001 \\
\hline
\end{tabular}

Fonte: Dados da pesquisa.

Tomando-se por base o valor do $\mathrm{t}_{t a b}$ elado de 1,96 $\left(\mathrm{t}_{t a b}=1,96\right)$ para o nível de significância de $5 \%(\alpha=0,05)$, observa-se que a diferença entre as médias de participação em projetos de pesquisas (PP) nos períodos antes e durante o mestrado não é significativa $\left(\mathrm{t}_{c a l} 1,377<\mathrm{t}_{\text {tab }} 1,96\right)$, nem mesmo a diferença entre os períodos antes e após o mestrado $\left(\mathrm{t}_{c a l}-1,00<\mathrm{t}_{\text {tab }}-1,96\right)$. No entanto, em se tratando da publicação de artigos, mostraram-se significativas as diferenças entre as médias das variáveis artigos publicados em periódicos (AP) antes e durante o mestrado $\left(\mathrm{t}_{c a l}-5,607>\mathrm{t}_{t a b}-1,96\right)$ e antes e após o mestrado $\left(\mathrm{t}_{c a l}-3,846>\mathrm{t}_{t a b}-1,96\right)$, e artigos publicados em eventos (AE) antes e durante o mestrado $\left(\mathrm{t}_{c a l}-9,749>\mathrm{t}_{t a b}\right.$ $-1,96)$ e antes e após o mestrado $\left(\mathrm{t}_{c a l}-3,35>\mathrm{t}_{t a b}-1,96\right)$. Essas diferenças ratificam a influência do mestrado na produção científica do mestre em Ciências Contábeis e, conseqüentemente, em seus desempenhos acadêmicos.

\subsection{Análise da Produção Científica dos Respondentes}

Quando a análise da produção científica se limita aos mestres respondentes do questionário, observa-se que apenas $30,85 \%$ deles participam de algum grupo de pesquisa no momento da realização deste estudo $(69,15 \%$ não participam de grupos de pesquisa). Quanto à participação em projetos de pesquisa e à publicação de artigos em periódicos e em eventos, observa-se que os números dos respondentes que compuseram a amostra da pesquisa seguem a tendência dos números apresentados pela população total.

A Tabela 3 demonstra que os mestres que compuseram a amostra concentram sua participação em projetos de pesquisa nos períodos pós-ingresso no mestrado. Do total de projetos realizados por eles, verifica-se que, 24,32\% (9 projetos) foram realizados no período anterior ao mestrado, $16,22 \%$ (6 projetos) no período durante o decurso do mestrado e outros $59,46 \%$ (22 projetos) no 
período após o mestrado. Quando o foco é a produção e publicação de artigos em periódicos, observa-se que apenas cerca de $11,18 \%$ deles (17 artigos) foram publicados antes do ingresso no mestrado, 44,74\% (68 artigos) durante o mestrado e 44,08\% (67 artigos) após o mestrado. Já quanto aos artigos publicados em eventos, nota-se uma tendência similar à apresentada pela população total, onde a maioria dos trabalhos foi publicada nos períodos durante e após o mestrado. Deste total de 823 trabalhos, 9,36\% (77 artigos) foram publicados antes do ingresso no mestrado, 53,10\% (437 artigos) durante o mestrado e 37,54\% (309 artigos) após a conclusão do mestrado.

Tabela 3: Produção científica dos mestres em Ciências Contábeis componentes da amostra

\begin{tabular}{|c|c|c|c|c|c|c|c|c|}
\hline \multirow{2}{*}{ Variável } & \multicolumn{2}{|c|}{ Produção } & \multirow{2}{*}{ Mín. } & \multirow{2}{*}{ Máx. } & \multirow{2}{*}{ Média } & \multirow{2}{*}{ Erro } & \multirow{2}{*}{$\begin{array}{l}\text { Desvio } \\
\text { Padrão }\end{array}$} & \multirow{2}{*}{ Variância } \\
\hline & $\mathbf{N}$ & $\%$ & & & & & & \\
\hline Participação em Projetos de Pesquisa & & & & & & & & \\
\hline Antes do mestrado & 9 & 24,32 & 0 & 4 & 0,10 & 0,05 & 0,47 & 0,22 \\
\hline Durante o mestrado & 6 & 16,22 & 0 & 2 & 0,06 & 0,03 & 0,32 & 0,10 \\
\hline Após o mestrado & $\underline{22}$ & $\underline{59,46}$ & 0 & 5 & 0,23 & 0,08 & 0,81 & 0,65 \\
\hline Total & $\overline{37}$ & $\overline{100,00}$ & & & & & & \\
\hline Artigos Publicados em Periódicos & & & & & & & & \\
\hline Antes do mestrado & 17 & 11,18 & 0 & 5 & 0,18 & 0,07 & 0,67 & 0,45 \\
\hline Durante o mestrado & 68 & 44,74 & 0 & 4 & 0,72 & 0,11 & 1,06 & 1,13 \\
\hline Após o mestrado & $\underline{67}$ & $\underline{44,08}$ & 0 & 10 & 0,71 & 0,18 & 1,78 & 3,15 \\
\hline Total & $\overline{152}$ & $\overline{100,00}$ & & & & & & \\
\hline Artigos Publicados em Anais de Eventos & & & & & & & & \\
\hline Antes do mestrado & 77 & 9,36 & 0 & 14 & 0,82 & 0,21 & 2,01 & 4,04 \\
\hline Durante o mestrado & 437 & 53,10 & 0 & 23 & 4,65 & 0,46 & 4,42 & 19,56 \\
\hline Após o mestrado & $\underline{309}$ & $\underline{37,54}$ & 0 & 39 & 3,29 & 0,78 & 7,54 & 56,87 \\
\hline Total & 823 & 100,00 & & & & & & \\
\hline
\end{tabular}

Fonte: Dados da pesquisa.

$\mathrm{A}_{T a b}$ ela 4 apresenta o teste de diferença entre duas médias para estas variáveis. Para as variáveis participação em projetos de pesquisa (PP) antes e durante o mestrado, o teste revelou não haver significância estatística entre a diferença de média apresentada $\left(\mathrm{t}_{c a l} 0,831<\mathrm{t}_{t a b} 1,96\right)$, no entanto, para as variáveis participação em projetos de pesquisa antes e após o mestrado, verificou-se uma diferença significativa $\left(\mathrm{t}_{c a l}-2,014>\mathrm{t}_{t a b}-1,96\right)$. Para as variáveis artigos publicados em periódicos (AP) antes e durante o mestrado $\left(\mathrm{t}_{c a l}-4,765>\mathrm{t}_{\text {tab }}-1,96\right)$ e antes e após o mestrado $\left(\mathrm{t}_{c a l}-2,74>\mathrm{t}_{t a b}-1,96\right)$, pode-se observar que há significância estatística entre as diferenças de médias. Quanto às variáveis artigos publicados em eventos (AE) antes e durante o mestrado $\left(\mathrm{t}_{c a l}-8,606>\mathrm{t}_{\text {tab }}-1,96\right)$ e antes e após o mestrado $\left(\mathrm{t}_{c a l}\right.$ $\left.-3,119>\mathrm{t}_{t a b}-1,96\right)$, o teste de diferença entre duas médias revelou também haver diferenças significativas entre as médias.

Tabela 4: Teste t de diferença entre duas médias para amostras emparelhadas - compo- 
nentes da amostra

\begin{tabular}{|c|c|c|c|c|c|c|c|c|c|}
\hline \multirow{3}{*}{\multicolumn{2}{|c|}{ Pair }} & \multicolumn{5}{|c|}{ Paired Differences } & \multirow[b]{3}{*}{$\mathrm{T}$} & \multirow{3}{*}{$\begin{array}{l}\mathrm{D} \\
\mathrm{F}\end{array}$} & \multirow{3}{*}{$\begin{array}{c}\text { Sig. } \\
\text { (2-tailed) }\end{array}$} \\
\hline & & \multirow[b]{2}{*}{ Mean } & \multirow{2}{*}{$\begin{array}{c}\text { Std. } \\
\text { Deviation } \\
\end{array}$} & \multirow{2}{*}{$\begin{array}{l}\text { Std. } \\
\text { Error } \\
\text { Mean }\end{array}$} & \multicolumn{2}{|c|}{$\begin{array}{c}95 \% \\
\text { Confidence } \\
\text { Interval of the } \\
\text { Difference }\end{array}$} & & & \\
\hline & & & & & Lower & Upper & & & \\
\hline Pair 1 & PP Antes - PP Durante & 0,032 & 0,372 & 0,038 & $-0,044$ & 0,108 & 0,831 & 93 & 0,408 \\
\hline Pair 2 & PP Antes - PP Depois & $-0,138$ & 0,666 & 0,069 & $-0,275$ & $-0,002$ & $-2,014$ & 93 & 0,047 \\
\hline Pair 3 & AP Antes - AP Durante & $-0,543$ & 1,104 & 0,114 & $-0,769$ & $-0,316$ & $-4,765$ & 93 & 0,000 \\
\hline Pair 4 & AP Antes - AP Depois & $-0,532$ & 1,882 & 0,194 & $-0,917$ & $-0,146$ & $-2,740$ & 93 & 0,007 \\
\hline Pair 5 & AE Antes - AE Durante & $-3,830$ & 4,315 & 0,445 & $-4,714$ & $-2,946$ & $-8,606$ & 93 & 0,000 \\
\hline Pair 6 & AE Antes - AE Depois & $-2,468$ & 7,672 & 0,791 & $-4,039$ & $-0,897$ & $-3,119$ & 93 & 0,002 \\
\hline
\end{tabular}

Fonte: Dados da pesquisa.

Desta forma, os resultados dos testes ratificam a influência do mestrado na produção científica dos mestres, uma vez que confirmaram a influência do título na participação em projetos de pesquisa e na publicação de artigos.

\subsubsection{Análise da Produção Científica por Núcleo do Programa}

Considerando-se a produção científica apresentada pelos egressos de cada um dos núcleos, percebe-se que no núcleo Brasília apenas 20\% dos mestres em Ciências Contábeis participam de algum grupo de pesquisa. Já no Nordeste, essa freqüência é maior, ao passo que 38,89\% dos respondentes participam de algum grupo.

Quanto às participações em projetos de pesquisa, percebe-se que, no núcleo Brasília, nenhum dos mestres participou de algum projeto antes ou durante o mestrado, concentrando uma pequena participação neste tipo de produção no período pós-mestrado, com apenas 4 (quatro) projetos. Já no núcleo Nordeste, há uma freqüência maior de participação em projetos, com um total de 33 projetos, sendo 54,55\% desses projetos realizadas no período pós-mestrado (18 projetos). Quanto à produção e publicação de artigos em periódicos, os egressos do núcleo Nordeste apresentam quase o dobro de trabalhos publicados. Enquanto em Brasília os mestres publicaram 53 artigos, sendo a maioria durante o decurso do mestrado $(47,17 \%)$, no Nordeste os respondentes publicaram 99 trabalhos, sendo a maioria publicada após o mestrado (46,47\%).

Essa é uma tendência também observada na publicação de artigos em eventos, variável na qual os respondentes do núcleo Nordeste apresentam uma significativa vantagem. Em Brasília, observou-se um total de 253 artigos publi- 
cados em eventos, sendo a maioria publicada no período de decurso do mestrado $(62,84 \%)$, fato similar ocorrido no Nordeste, onde houve a publicação de 570 artigos, conforme Tabela 5. Isso denota que há uma desaceleração da produção de trabalhos científicos por parte do mestre após a conclusão do mestrado.

Tabela 5: Produção científica dos mestres em Ciências Contábeis componentes da amostra, por núcleo

\begin{tabular}{|c|c|c|c|c|c|c|}
\hline \multirow{2}{*}{ Variável } & \multicolumn{3}{|c|}{ Núcleo Brasília } & \multicolumn{3}{|c|}{ Núcleo Nordeste } \\
\hline & $\mathbf{N}$ & $\%$ & Média & $\mathbf{N}$ & $\%$ & Média \\
\hline Participação em Projetos de Pesquisa & & & & & & \\
\hline Antes do mestrado & 0 & 0,00 & 0,00 & 9 & 27,27 & 0,17 \\
\hline Durante o mestrado & 0 & 0,00 & 0,00 & 6 & 18,18 & 0,11 \\
\hline Após o mestrado & 4 & 100,00 & 0,10 & 18 & 54,55 & 0,33 \\
\hline Total & $\overline{4}$ & $\overline{100,00}$ & & $\overline{33}$ & $\overline{100,00}$ & \\
\hline Artigos Publicados em Periódicos & & & & & & \\
\hline Antes do mestrado & 7 & 13,21 & 0,18 & 10 & 10,10 & 0,19 \\
\hline Durante o mestrado & 25 & 47,17 & 0,63 & 43 & 43,43 & 0,80 \\
\hline Após o mestrado & $\underline{21}$ & $\underline{39,62}$ & 0,53 & $\underline{46}$ & $\underline{46,47}$ & 0,85 \\
\hline Total & $\overline{53}$ & $\overline{100,00}$ & & $\overline{99}$ & $\overline{100,00}$ & \\
\hline Artigos Publicados em Anais de Eventos & & & & & & \\
\hline Antes do mestrado & 15 & 5,93 & 0,38 & 62 & 10,88 & 1,15 \\
\hline Durante o mestrado & 159 & 62,84 & 3,98 & 278 & 48,77 & 5,15 \\
\hline Após o mestrado & $\underline{79}$ & $\underline{31,23}$ & 1,98 & $\underline{230}$ & $\underline{40,35}$ & 4,26 \\
\hline Total & 253 & 100,00 & & 570 & 100,00 & \\
\hline
\end{tabular}

Fonte: Dados da pesquisa .

Frente a estes números, nota-se uma tendência mais acentuada dos egressos do núcleo Nordeste em produzirem e publicarem pesquisas científicas, embora ainda haja uma desaceleração dessa produção após a conclusão do mestrado nos dois núcleos. No panorama mundial, a participação brasileira nas publicações científicas atinge cerca de $1,3 \%$ de toda a pesquisa publicada. Castro (2002) observa que somos os segundos produtores de pesquisas científicas, considerando-se que grande parte das publicações atribuídas a Taiwan e Coréia são escritas fora dos seus países de origem. Mas mesmo que incluamos estes dois países, o Brasil ainda ocupa uma posição muito expressiva, resultado direto e imediato da criação de uma pós-graduação sólida e relativamente grande.

\subsubsection{Análise da Produção Científica por Gênero}

Do total de respondentes (96), 63 são homens e 33 mulheres. Nesse sentido, focalizando a análise da participação em grupos de pesquisa com base no gênero, observa-se que existe um equilíbrio. Entre os homens, a freqüência de participação representa $30,16 \%$, enquanto entre as mulheres $30,30 \%$. Quanto à participação em projetos de pesquisa, observa-se que tanto os homens quanto as 
mulheres concentram sua maior participação no período após o mestrado.

Em se tratando da publicação de artigos, tanto em periódicos como em eventos, nota-se que, antes do ingresso no mestrado os homens apresentam uma pequena vantagem sobre as mulheres em se tratando de média de publicação (0,25 a 0,03 em periódicos e 0,87 a 0,67 em eventos), entretanto, quando a análise limita-se aos períodos durante e após o mestrado, as mulheres apresentam médias significativamente superiores às dos homens, como pode ser observado na Tabela 6.

Tabela 6: Produção científica dos mestres em Ciências Contábeis componentes da amostra, por gênero

\begin{tabular}{|c|c|c|c|c|c|c|}
\hline \multirow{2}{*}{ Variável } & \multicolumn{3}{|c|}{ Homens } & \multicolumn{3}{|c|}{ Mulheres } \\
\hline & $\mathbf{N}$ & $\%$ & Média & $\mathbf{N}$ & $\%$ & Média \\
\hline Participação em Projetos de Pesquisa & & & & & & \\
\hline Antes do mestrado & 6 & 25,00 & 0,10 & 3 & 23,08 & 0,09 \\
\hline Durante o mestrado & 6 & 25,00 & 0,10 & 0 & 0,00 & 0,00 \\
\hline Após o mestrado & $\underline{12}$ & $\underline{50,00}$ & 0,19 & $\underline{10}$ & 76,92 & 0,30 \\
\hline Total & $\overline{24}$ & $\overline{100,00}$ & & $\overline{13}$ & $\overline{100,00}$ & \\
\hline Artigos Publicados em Periódicos & & & & & & \\
\hline Antes do mestrado & 16 & 18,39 & 0,25 & 1 & 1,54 & 0,03 \\
\hline Durante o mestrado & 42 & 48,28 & 0,67 & 26 & 40,00 & 0,79 \\
\hline Após o mestrado & 29 & $\underline{33,33}$ & 0,46 & $\underline{38}$ & $\underline{58,46}$ & 1,15 \\
\hline Total & 87 & $\overline{100,00}$ & & $\overline{65}$ & $\overline{100,00}$ & \\
\hline Artigos Publicados em Anais de Eventos & & & & & & \\
\hline Antes do mestrado & 55 & 11,80 & 0,87 & 22 & 6,16 & 0,67 \\
\hline Durante o mestrado & 251 & 53,86 & 3,98 & 186 & 52,10 & 5,64 \\
\hline Após o mestrado & $\underline{160}$ & $\underline{34,34}$ & 2,54 & $\underline{149}$ & $\underline{41,74}$ & 4,52 \\
\hline Total & 466 & 100,00 & & 357 & 100,00 & \\
\hline
\end{tabular}

Fonte: Dados da pesquisa.

Considerando-se a influência do mestrado na produção científica destes mestres, observa-se que a diferença entre a quantidade de artigos publicados antes do ingresso no mestrado e após este ingresso (durante e após o curso) é significativa, ao passo que estes mestres apresentaram produção bem superior nos períodos durante e após o curso, sejam homens ou mulheres. No entanto, nota-se que as mulheres apresentaram uma evolução em sua produção científica superior a dos homens, uma vez que estas possuem médias de artigos publicados superiores a dos homens em todas as variáveis que envolvem tais publicações após o ingresso no mestrado. Entretanto, em ambos os gêneros ainda é possível observar uma desaceleração na produção deste tipo de pesquisa no período pós-mestrado, tomando-se como base as médias de produção apresentadas no período durante o mestrado (embora entre as mulheres esta desaceleração seja menor).

\section{Considerações Finais}


Apoiando-se em uma base teórica que trata da Teoria do Capital Humano e em um breve relato histórico sobre a pós-graduação em Ciências Contábeis e, mais especificamente sobre o Programa Multiinstitucional, partiu-se para a investigação sobre a influência do título de mestre em Ciências Contábeis na produção científica dos mestres egressos do Programa Multiinstitucional e Inter-Regional de Pós-Graduação em Ciências Contábeis da UnB/UFPB/UFPE/UFRN. No tocante a isto, cinco importantes conclusões podem ser enumeradas:

1. Analisando-se a população investigada, pode-se observar que apenas $27,48 \%$ dos mestres participam de algum grupo de pesquisa, a maior parte dos projetos de pesquisa nos quais participavam foi criada no período após o mestrado, de forma similar a publicação de artigos em periódicos e em eventos.

2. Quando a análise resume-se aos mestres componentes da amostra, nota que o percentual de mestres que participam de algum grupo de pesquisa segue a tendência geral $(30,85 \%)$. Quanto à participação em projetos e à publicação de artigos, sua maioria também se concentra nos períodos pós-ingresso no mestrado.

3. Investigando a influência desta titulação à produção dos egressos de cada um dos núcleos do Programa, percebe-se a influência positiva em ambos, notando-se que os egressos do núcleo Nordeste apresentam médias de publicação superiores aos do núcleo Brasília, denotando serem mais produtivos.

4. Quando a análise se restringe ao gênero do mestre, nota-se que a titulação é igualmente influente à produção de homens e mulheres, embora as mulheres tenham apresentado melhores resultados.

5. Ratificando os resultados observados, os testes de diferenças entre médias comprovaram a significância estatística entre as médias de participação em projetos de pesquisa e de publicação de artigos em periódicos e em eventos, tanto da população total quanto da amostra investiga. Entretanto, pode-se observar uma desaceleração na produção média destes mestres após a conclusão de seus cursos, nos dois núcleos e entre homens e mulheres, embora o núcleo Nordeste e as mulheres tenham apresentado uma desaceleração menor.

Por fim, faz necessário observar que a pesquisa aqui realizada foi restrita aos mestres em Ciências Contábeis titulados por um único programa de pósgraduação, em um determinado período de tempo. Ainda, ela limita-se a uma análise quantitativa deste quadro. Com vistas a estas limitações, os resultados ora apresentados representam apenas um recorte da realidade em questão, não possuindo a intenção de serem colocados como respostas definitivas ao pro- 
blema investigado. Entretanto, observa-se que, considerando seus achados e a escassez de estudos sobre esta temática, tais limitações não invalidam o estudo. Ainda, sugere-se que sejam realizados novos estudos, buscando evidenciar novas tendências, inclusive, focalizando os aspectos qualitativos dessa influência na publicação dos mestres.

Referências

ANPCONT - Associação Nacional dos Programas de Pós-Graduação em Ciências Contábeis. Quantidade de mestres e doutores titulados por instituição. Disponível em: http://www.anpcont.com.br/arquivos/pesquisa_pos2005.pdf. Acesso em: 30 mai. 2008.

BEUREN, I. M. (org.). Como elaborar trabalhos monográficos em contabilidade: teoria e prática. 3. ed. São Paulo: Atlas, 2006.

CAPES - Coordenação de Aperfeiçoamento de Pessoal de Nível Superior. Discussão da pós-graduação brasileira. Brasília: MEC, 1996.

CASTRO, C. M. A pós-graduação e a CAPES: o que deu certo e o que deve ser feito. Boletim Informativo INFOCAPES, Brasília, v. 10, n. 2, p. 138-143, abr./ jun. 2002.

CUNHA, J. V. A. Doutores em ciências contábeis da FEA-USP: análise sob a óptica da teoria do capital humano. 2007. 261f. Tese (Doutorado em Contabilidade e Controladoria) - Faculdade de Economia, Administração e Contabilidade, USP, São Paulo, 2007.

GIL, A. C. Métodos e técnicas de pesquisa social. 5. ed. São Paulo: Atlas, 1999.

IUDÍCIBUS, S.; MARION, J. C. Considerações sobre os cursos de pós-graduação em Contabilidade. Boletim do Ibracon, São Paulo, v. 26, n. 186, p. 02-07, 1993.

KAZMIER, L. J. Estatística aplicada à Economia e Administração. Trad. Carlos Augusto Crusius. São Paulo: Pearson Makron Books, 1982.

MACHADO, M. R. O resultado econômico-financeiro proporcionado aos profissionais mediante conclusão de curso de pós-graduação lato sensu em contabilidade, 1988 - 2001. 2003. 150f. Dissertação (Mestrado em Ciências Contábeis) - Programa Multiinstitucional e Inter-Regional de Pós-Graduação em 
Ciências Contábeis, UnB/UFPB/UFPE/UFRN, João Pessoa, 2003.

MOREL, R.L.M. Ciência e Estado: a política científica no Brasil. São Paulo: Queiroz, 1979.

NIYAMA, J. K. I.F.R.S. - Convergência internacional: desafios sob a visão da academia e da profissão contábil. Disponível em: http://www.crc-ce.org.br/ crcnovo/files/I.F.R.S_covergencia_4.pdf. Acesso em: 17 dez. 2008.

PELEIAS, I. R.; et. al. Evolução do ensino da contabilidade no Brasil: uma análise histórica. Revista Contabilidade \& Finanças, São Paulo, Ed. 30 anos dourados, p. 19-32, jun. 2007.

RICHARDSON, R. J. Pesquisa social: métodos e técnicas. 3. ed. São Paulo: Atlas, 2008.

SILVA, A. C. R. Metodologia da pesquisa aplicada à contabilidade: orientações de estudos, projetos, artigos, relatório, monografias, dissertações, teses. São Paulo: Atlas, 2003.

SILVA, M. C. F. Pós-graduação stricto sensu e desenvolvimento regional. Publicatio UEPG - Ciências Humanas, Ciências Sociais Aplicadas, Lingüística, Letras e Artes, Ponta Grossa, v. 16, n. 1, p. 55-60, jun. 2008.

UNB - Universidade de Brasília. Mestrado: o programa. Disponível em: http:// www.unb.br/cca. Acesso em: 01 fev. 2008a.

UNB - Universidade de Brasília. Mestrado: ingressantes por semestre. Disponível em: http://www.spl.unb.br/isapi/m_ing.dll/ingsem. Acesso em: 24 jan. 2008 b.

VELlOSO, J.; VELHO, L. Mestrandos e doutorandos no país: trajetórias de formação. Brasília: CAPES, 2001.

\section{Notas}

[1] Lei no 9.394/96, Artigo no 52, Incisos II e III, que tratam da exigência de pelo menos um terço do corpo docente possuir titulação acadêmica de mestrado ou doutorado, e de um terço dos docentes possuírem regime de tempo integral.

${ }^{2}$ ] Até antes à saída da UFPE do Programa. Após a saída, o Programa continuou com apenas duas Coordenações Regionais. 
